\title{
Balancing confidence and conservatism: idiopathic scoliosis in an adult powerlifter
}

\author{
Rohit Malyala
}

\section{THE DIAGNOSIS-AND}

COMMUNICATION-OF MY SCOLIOSIS

Growing up I had never given much thought to occasional back pains, nor to the asymmetries of my body, whether I noticed it in my legs, my ribs or my shoulders. Pain was as irritating to me as it might be for anybody else, but without an explanation for the experience, it was easy to not let the sensations overwhelm me. Everybody experiences discomfort every now and again, and mine were certainly not debilitating enough to change anything about my life.

One day, while being treated for an unrelated wrist injury, my family doctor noticed some of those asymmetries. While the growing pain had generally stopped-I was 17 now-she referred me for an X-ray, and I obliged. In the follow-up I was told that I had scoliosis, with two curves. I was told that there was a risk of the curves progressing, and that I should take steps to avoid such progression. She referred me to a community physiotherapist, and recommended that I self-monitor my posture. I obliged again, attending physiotherapy three times a week. I also started to avoid engaging in other physical activities.

My curves, with hindsight, were not at all severe. But at the time, I grew fearful. My mind started piecing together strange narratives, associating old growing pains as some bizarre consequence of my everworsening spinal deformity. I found it easy to catastrophise, and every minor ache in my back compounded as I became more and more sedentary, afraid to move and be active and do the things that any other 17-year-old would do without thinking. Whatever difficulties I might have had worsened, and I found myself even having trouble breathing, feeling my ribs newly and painfully curling inward into my lungs.

It was overly convenient for the pains of my (moderate) scoliosis to have physically worsened so severely just weeks after diagnosis. I imagine now

Correspondence to Rohit Malyala, Faculty of Health Sciences, McMaster University, Hamilton, ON L8S 4L8, Canada; rohitml2013@gmail.com that the pain was both stress-related, and from all the extra time I spent inactive, making my back weaker physically. While my physician had said or done nothing wrong in her recommendations, as a patient I had interpreted her words in a way that had made me feel weaker. That impact to my self-concept was not only intrinsically problematic, but had worsened my physical pain experience.

\section{Introduction to, and fears surrounding heavy training}

Many months later, I began to develop an interest in weight loss and fitness. I think a large part of the fear I had initially coming into the gym-not even heavy powerlifting, but even just working out on machines and doing simple bicep curls-was the vague sense of conservatism towards my spine that had been instilled in me through my clinical experiences. The incredibly delicate, light-weight exercises I had done with my physiotherapist had made me feel like that was how I needed to live my life, at large.

In my own intuition, doing any intense weightlifting was going to compress my spine, and worsen the curvature. I started to try to understand my condition with my own research, moving quickly from online blogs to public health forums to medical literature. Many online forums also endorsed avoiding heavy squatting and deadlifting, but I never found any explicit research discussing the weightlifting and scoliosis specifically. Nevertheless, reconciling my manufactured feelings of self-conservatism, and wanting to be stronger was difficult.

Thankfully, being brought and welcomed into the gym with help from friends and kind strangers alike, I slowly waded into more and more intense strength training. Eventually, I reached a point where I started squatting over $300 \mathrm{lb}$ and deadlifting $400 \mathrm{lb}$ as part of routine training (weighing 140-150 lb). At this point, I started to stop overthinking my scoliosis entirely.
Personal and clinical outcomes

Even very quickly after entering the gym, I noticed two major changes in my condition. Physically, the intermittent back pain and breathing troubles I had went away entirely as I started developing genuine back strength. And mentally, my scoliosis and all the negative self-concept associated with it totally left my mind. In a very general sense I felt fundamentally empowered even outside the gymin my interactions with other people, in my posture and gait. I felt stronger in a million different ways.

I have recently taken another fullspine X-ray and thankfully, neither of my curves worsened. But even if they had, I would still not have regretted my time in powerlifting. I understand now that it is not the degree of the curvature that dictates my quality of life, but how I actually feel from day-to-day.

During a later physical exam, I asked my family doctor how she felt about powerlifting or strongman sports for someone with my curvature. She said that while she would not recommend strength sports for people with scoliosis, she was happy to hear the positive benefits I had experienced through my training. It was powerful and meaningful to hear this from my doctor; avoiding admonishing people in my position can make us feel safer in our course of action.

I appreciate the management difficulty that I presented for my doctor as a scoliosis patient who wanted to engage in more intense physical activity. From my own experience alone, I would not presume to give concrete advice to encourage all types of physical activity for all types of scoliosis. But I also believe there is so much untapped value in getting people with scoliosis to do more than just low-impact activities like yoga and swimming-something more challenging, something more intense.

\section{Advice for clinicians working with} youths or athletes with scoliosis

1. Try to encourage more intense sports over traditionally low-impact activities. Engaging in traditionally 'tougher' activities may help build resilience against feelings of fragility.

2. Even a well-delivered diagnosis and work-up can cause anxiety. Make sure to explicitly warn patients against catastrophising, and how unwarranted anxiety can exacerbate or even outright cause pain. 


\section{Patient voices}

3. Take time to emphasise to patients that degree of curvature is not equivalent to quality of life.

Contributors RM: writing of manuscript.

Funding The authors have not declared a specific grant for this research from any funding agency in the public, commercial or not-for-profit sectors.
Competing interests None declared.

Patient consent for publication Obtained.

Provenance and peer review Not commissioned; internally peer reviewed.

(C) Author(s) (or their employer(s)) 2020. No commercial re-use. See rights and permissions. Published by BMJ.

D Check for updates
To cite Malyala R. Br J Sports Med 2020;54:943-944.

Accepted 4 September 2019

Published Online First 18 September 2019

Br J Sports Med 2020;54:943-944. doi:10.1136/bjsports-2019-100925

\section{ORCID iD}

Rohit Malyala http://orcid.org/0000-0003-2074-5002 